\title{
Evaluation of Technology for the Analysis and Forecasting of Precipitation Using Cyclostationary EOF and Regression Methods
}

Mingdong Sun ( $\nabla$ mingdongsun@hotmail.com )

Chinese Research Academy of Environmental Sciences https://orcid.org/0000-0002-1511-7688

\section{Gwangseob Kim}

Kyungpook National University College of Engineering

\section{Yan Wang}

Chinese Research Academy of Environmental Sciences

Kun Lei

Chinese Research Academy of Environmental Sciences

\section{Research Article}

Keywords: Precipitation forecasting, Empirical orthogonal function (EOF), Cyclostationary empirical orthogonal function (CSEOF), Seasonal cycle, Autoregressive moving average (ARMA), Climate change.

Posted Date: July 19th, 2021

DOl: https://doi.org/10.21203/rs.3.rs-245667/v1

License: (c) (i) This work is licensed under a Creative Commons Attribution 4.0 International License. Read Full License

Version of Record: A version of this preprint was published at Atmosphere on March 21st, 2022. See the published version at https://doi.org/10.3390/atmos13030500. 
2 Evaluation of Technology for the Analysis and Forecasting of Precipitation Using Cyclostationary EOF and Regression Methods

4

5

Mingdong Sun ${ }^{1}$, Gwangseob Kim ${ }^{2}$, Yan Wang ${ }^{1}$, Xiangqin $\mathrm{Xu}^{1}$ and Kun Lei ${ }^{1}$

6

7

8

9 Corresponding author : 1.Kun Lei, 2.Yan Wang

10 Email: $\underline{\text { leikun@craes.org.cn }}$

11 wang.yan@craes.org.cn

$12{ }^{1}$ Chinese Research Academy of Environmental Sciences, Beijing 100012, China

$13{ }^{2}$ Department of Civil Engineering, Kyungpook National University, Daegu 702701, Republic of Korea 14 
Precipitation time series exhibit complex fluctuations and statistical changes. We investigate and forecast precipitation variations in South Korea from 1973 to 2019 using cyclostationary empirical orthogonal function (CSEOF) and regression methods. First, empirical orthogonal function (EOF) and CSEOF analyses are used to examine the periodic changes in the precipitation data. Then, the autoregressive moving average (ARMA) method is applied to the principal component (PC) time series derived from the EOF and CSEOF precipitation analyses. The fifteen leading EOF and CSEOF modes and their corresponding PC time series clearly reflect the spatial distribution and temporal evolution characteristics of the precipitation data. Based on the PC forecasts of the EOF and CSEOF models, the EOF-ARMA composite model and CSEOF-ARMA composite model are used to obtain quantitative precipitation forecasts. The comparison results show that both composite models have good performances and similar accuracies. However, the performance of the CSEOF-ARMA model is better than that of the EOFARMA model under various measurements. Therefore, the CSEOF-ARMA composite forecast model can be considered an efficient and feasible technology representing an analytical approach for precipitation forecasting in South Korea.

Key words: Precipitation forecasting; Empirical orthogonal function (EOF); Cyclostationary empirical orthogonal function (CSEOF); Seasonal cycle; Autoregressive moving average (ARMA); Climate change.

\section{Introduction}

Global climate and environmental changes have become major worldwide issues in recent years. In particular, interactions between the atmosphere and slowly changing oceans will have profound and longterm effects on humans. Because agricultural production and hydrological management are heavily influenced by the climate, meteorologists are interested in the effects of climate and environmental changes, such as variations in periodic meteorological phenomena (Trenberth 1990).

Precipitation is an important variable in climate change research. It is the main component of the water cycle and has a great influence on surrounding environments and hydrological systems. Changes in the timing and amount of precipitation in a given area can lead to serious flood hazards or agricultural failures 
due to floods and droughts. Because human-induced climate change accelerates the hydrological cycle of the ecosystem, forecasting precipitation on the decadal scale is becoming increasingly important for long-term water resource management (Huntington 2006; Oki and Kanae 2006). Advanced precipitation forecasting technologies and timely precipitation diagnoses can help improve the operation of water storage facilities and prevent potential flood disasters. The latest Intergovernmental Panel on Climate Change report indicated that there is growing concern in the scientific community regarding the significant increases observed in the amount and intensity of precipitation and regarding the corresponding variations (Nicholls and Alexander 2007).

Much research has been conducted regarding forecasting precipitation, with many studies highlighting that the trends observed in the annual and monthly precipitation of different regions depend on the region of interest and the time period examined (Becker et al. 2006; Lim and Kim 2006; Zhou and Wang 2006). Several studies have focused on seasonal predictions of precipitation at the regional level using different technologies, such as regional climate models (Kim et al. 2000), in conjunction with other climate variables (Higgins et al. 2004; Wang et al. 1999). Some studies have improved the approaches used to forecast climate index values, such as projections with teleconnection indices (Silverman and Dracup 2010) and the development other ensemble forecasting models (Block and Rajagopalan 2007; Peel and Wilson 2008). In addition, many studies have closely investigated the various trends and spatiotemporal characteristics of precipitation in South Korea (Chang and Kwon 2007; Jin et al. 2005; Kim and Kim 2004; Wang et al. 2006).

In general, traditional statistical methods are typically used for long-range forecasting, with the incorporation of dynamical methods contributing improvements. Some successful approaches have involved performing climate forecasting using multiple regression and correlation analysis methods (Barnston et al. 1999; Vautard et al. 1999; Waliser et al. 1999; Waliser et al. 2003; Webster and Hoyos 2004). Many climatic variables, such as precipitation, surface temperature, and solar flux, are known to exhibit periodic (annual, monthly, daily, etc.) variations in their statistical features. Analyses of such datasets performed using stationary approaches often yield meaningless statistical characteristics, representing the weak error correction performances of these methods and their inaccuracy in obtaining long-term 
for statistical analyses of climatic phenomena that display strong cyclical trends.

71 Precipitation has typical cyclical variations with statistical fluctuations and seasonal tendencies. Par-

72 ticularly when a precipitation dataset covers several weather stations or spans different seasons, station-

73 ary methods can be used to obtain only the most obvious statistical trends. In climate studies, empirical

74 orthogonal function (EOF) analyses are often used to study possible spatial patterns of variability and

75 how these patterns change with time. Some studies have used EOF models to analyze precipitation data.

76 Cahalan analyzed monthly precipitation data over the US and Canada based on EOFs and their variances

77 (Cahalan et al. 1996). Singh compared major rainfall patterns using the main modes of OLR data (Singh

78 2004). Svensson showed that most of the variance observed in rainfall in four periods could be explained

79 by an elongated spatial rainfall pattern (Svensson 1999). As such, EOF analyses are sometimes classified

80 as multivariate statistical techniques. However, EOF analyses are not based on physical principles. Thus,

81 to adequately analyze a comprehensive dataset, we use a cyclostationary empirical orthogonal function

82 (CSEOF) analysis technique; this approach is useful for extracting evolving spatial patterns.

83 This study primarily focuses on the analysis of the most dominant component of the seasonal cycle of 84 precipitation in South Korea. Empirical orthogonal function (EOF) and CSEOF analyses are conducted 85 to extract individual modes in the observed precipitation data to obtain the temporal and spatial evolution 86 of individual synoptic fields. We use EOF and CSEOF analyses as the primary techniques to analyze the 87 temporal evolution of the variability in precipitation and demonstrate the physical mechanism associated 88 with each mode of precipitation variability. The autoregressive moving average (ARMA) model is used to examine and forecast the evolution of the temporal modes of precipitation variability derived from the

90 EOF and CSEOF. Precipitation forecasts are generated from the regressed temporal and spatial patterns.

91 The present study provides a detailed explanation of the observed changes in precipitation variables and explores a feasible statistical methodology for forecasting precipitation in a monsoon climate.

93 The data used in this study are described in Section 2. The EOF and CSEOF analysis methods used to 94 analyze precipitation variability and the ARMA model are also explained in Section 2. The cyclical sea95 sonal characteristics of precipitation variability are presented in Section 3. The forecasting performance and related mechanisms are discussed in Section 4. Conclusions are presented in Section 5. 


\section{$98 \quad$ Data}

99 The primary data used in the present study were precipitation measurements taken over South Korea by

100 the Korea Meteorological Administration (KMA). A real-time quality control system was developed for

101 meteorological data measured by integrated meteorological sensors based on a comparison of quality

102 control procedures developed for meteorological data by the World Meteorological Organization and the

103 Korea Meteorological Administration (KMA). The 56 weather stations from which the data analyzed in

104 this study were collected are generally well distributed across the mainland, as shown in Fig. 1, while

105 data from Jejudo and Ulleungdo as well as some missing data were excluded from the analysis. The

106 dataset represents the longest and most consistent precipitation observations available in South Korea,

107 spanning 47 years (1973-2019). In this study, the data from the first 42 years (1973-2014) of the time

108 series are used to generate the forecasting model, while the last five years (2015-2019) of precipitation

109 records are used to validate the model.

\section{Methodology}

111 The statistical techniques used in this study include the application of EOFs and CSEOFs for decompos-

112 ing the data and ARMA models for forecasting precipitation.

\section{Empirical orthogonal function}

114 Empirical orthogonal function analyses (Lorenz 1956) are among the most widely applied techniques in

115 oceanography and atmospheric science research. In this method, a spatiotemporal dataset is decomposed

116 into orthogonal basis functions determined by the data. The method is similar to principal component

117 analysis; however, EOFs can detect both temporal and spatial patterns.

118 In EOF analyses, spatiotemporal data $X(r, t)$ are represented in terms of loading vectors $(L)$ and their

119 principal component $(P C)$ time series, as follows:

$$
X(r, t)=\sum_{n} P C_{n}(t) L_{n}(r)
$$

121 where $L_{n}(r)$ represents a specific spatial pattern and $P C_{\mathrm{n}}(t)$ represents the temporal evolution of $L_{n}(r)$.

122 This equation signifies a decomposition of a given dataset into a number of spatial and temporal patterns.

123 The spatial patterns are orthogonal to each other and are ordered by magnitude; the temporal patterns

124 oscillate over time. The loading vectors represent the independent patterns of variability in the dataset 
128 A CSEOF is the basic function in a cyclostationary process and is a cyclostationary analog of an EOF

129 obtained using a stationary approach (Kim et al. 1996). The CSEOF analysis method is described in 130 detail by Kim and North (Kim and North 1997). In CSEOF analyses, spatiotemporal data are represented 131 as follows:

$$
X(r, t)=\sum_{k=0}^{d-1} c_{k}(r, t) e^{2 \pi i k t / d}=\sum_{k=0}^{d-1} \sum_{m} c_{k m}(t) F_{l}(r) e^{2 \pi i k t / d}
$$

133 where $F_{l}(r)$ is any basis function and $\mathrm{d}$ is the nested period representing the inherent periodicity in the data.

$$
\text { By calculating the covariance function and the Bloch function, the space-time CSEOFs can be ob- }
$$
tained using the following equation:

$$
X(r, t)=\sum_{n} P C_{n}(t) C L_{n}(r, t)
$$

where $C L_{n}(r, t)$ is a cyclostationary loading vector (CSLV) and $P C_{n}(t)$ is the corresponding PC time series. In contrast to EOF analyses, the CSLVs are time-dependent. The temporal evolution of a spatial pattern also depends on periodic data with period $d$, calculated as follows.

$$
C L_{n}(r, t)=C L_{n}(r, t+d)
$$

Thus, CSLVs are periodic, time-dependent eigenfunctions of the covariance statistics.

An essential component in CSEOF analyses is determining the nested period. Selecting a proper nested period requires an adequate understanding of the physical and statistical characteristics of the dataset being analyzed (Kim and Chung 2001).

The CSEOF technique is conceptually similar to the EOF technique in that both extract sequences of spatial patterns as eigenfunctions based on the spatiotemporal structure of the covariance function. However, the major difference between EOF and CSEOF is that, in CSEOF analyses, each CSLV represents a set of spatial patterns. The critical motivation for the temporal dependence of CSLVs is that the spatial patterns of many known phenomena in climate science and geophysics evolve over time with recognizable periods while exhibiting slow fluctuations over longer time scales. A comparison of studies that used EOF and CSEOF techniques can be found in Kim and Wu (Kim and Wu 1999). Recent studies 
153 have demonstrated the efficacy of CSEOFs in extracting robust modes representing climate variabilities

154 (Kim and Roh 2010; Kim et al. 2004; Kim et al. 2013; Sun and Kim 2016).

155

\subsubsection{Autoregressive moving average}

The general autoregressive moving-average (ARMA) model was introduced by Box and Jenkins (Box and Jenkins 1971). This model is usually applied to estimate related values in a time series. An $\operatorname{ARMA}(p, q)$ model includes two types of terms: an autoregressive $\operatorname{AR}(p)$ term of order $\mathrm{p}$ and a movingaverage $\operatorname{MA}(q)$ term of order q. The autoregressive component involves regressing the studied variable on its own lagged values. The moving-average component involves modeling the error term as a linear combination of error terms occurring contemporaneously and at various times in the past. Thus, the model can be written as follows:

$$
X_{t}=\sum_{i=1}^{p} \alpha X_{t-1}+\sum_{j=1}^{q} \beta_{j} e_{t-j}+e_{t}
$$

where $X_{t}$ is the time series value, $\alpha$ and $\beta$ are the parameters of the model, and $e$ is white noise.

$$
\text { The key difficulty in applying the ARMA model is identifying the orders of the model. Numerous }
$$
available tests can be used to determine the orders of an ARMA model. Two common proposed methods include the Akaike information criterion (AIC) and the Bayesian information criterion (BIC) (Akaike 1974; Schwarz 1978).

\section{Results and Discussion}

\section{Seasonal cycle of precipitation}

The spatial distribution of mean precipitation in South Korea are shown in Fig. 2, where the distribution represents the precipitation interpolation at each weather station. The means of precipitation in Fig. 2 indicate the primary variabilities in precipitation. As expected, the mean (Fig. 2) is large in the north and south because of seasonal fluctuations in precipitation in the summer. The annual precipitation is approximately $1305 \mathrm{~mm}(1973-2019$ average), with more than $60 \%$ of the annual rainfall occurring between June and August. Boxplots of the monthly precipitation from 1973 to 2015 are plotted in Fig. 3. The annual periodicity involves obvious precipitation increases in the summer, with maximums occurring in July and August corresponding to the summer monsoon in Asia; precipitation is lower at other times of the year. 
181 main motivation for using these techniques is to investigate the mechanisms associated with changes in the variability of precipitation. A scree plot of the accumulated percents obtained in the EOF and CSEOF analyses is shown in Fig. 4 to show how they cumulatively rise. We present the two leading EOF and CSEOF modes to illustrate the temporal and spatial variations in precipitation.

Fig. 5 shows the first and second EOF modes, which explain $77.07 \%$ and $8.13 \%$ of the total variance, respectively. The PCs and loading patterns corresponding to the two leading modes are described in Fig. 5a and Fig. 5b by homogeneous correlation maps. The loading patterns in Fig. 5c and Fig. 5d come from interpolation based on dispersion points. represent special cycles with slight fluctuations over longer time scales than those seen in the CSEOF modes. The amplitude of the first PC (Fig. 5a) fluctuates over an annual cycle, similarly to the original precipitation data. The loading patterns of the first EOF mode (Fig. 5c) exhibit obvious symmetry between the north and south regions, and those of the second mode (Fig. 5d) exhibit an increase from north to south. is set to 12 months in the CSEOF analysis because the seasonal cycle is to be extracted. The first CSEOF mode of precipitation explains $73.55 \%$ of the total variance (Fig. 6). The PC time series of the first mode (Fig. 6a) and the cyclostationary loading patterns (Fig. 6b) are shown for 12 months, from January to December. The loading patterns are interpolated based on the dispersion points. This mode denotes the seasonal cycle. The most pronounced feature of the CSLVs is the slowly varying precipitation throughout

201 the year: the vectors indicate low rainfall from January to May, plenty of rainfall from June to September, 202 and decreasing rainfall from October to December. The corresponding PC time series exhibits interannual and decadal variations in the seasonal cycle, as well as an increasing trend that is significant but not 204 conspicuous, with stronger natural variability. seasonal cycle (the first mode) and adjusting for the seasonal cycle. The precipitation diminishes in April and then increases until July, decreases significantly in August and then increases until December. The 
208 PC time series of the second mode shows a positive phase shift in approximately 2006. Compared with 209 the years before 2006, more recent precipitation tends to be more extensive. Thus, the second mode 210 indicates slightly less precipitation in August and relatively large increases in precipitation in July.

211 In the EOF and CSEOF analyses, the 13 leading EOF modes and 15 leading CSEOF modes account 212 for $95.15 \%$ and $95.01 \%$ of the total variance, respectively; these modes are statistically significant and 213 distinct from the other modes; thus, they are selected for forecasting according to the rule of thumb 214 (North et al. 1982). The thirteen leading temporal modes from the EOF and fifteen modes form the 215 CSEOF can account above $95 \%$ of total variance are interpreted as the primary conditions for the for216 mation of precipitation, the remaining modes are considered as noise of data.

\section{Forecasting of precipitation}

Once the precipitation data have been decomposed into EOF and CSEOF modes, an ARMA model 219 is applied in the EOF and CSEOF space to derive precipitation variations in the PC time series. This 220 composition of analysis and regression methods results in two combined forecasting models: a combined 221 EOF-ARMA model and a combined CSEOF-ARMA model.

Forecasts of the temporal patterns and timescales of the PCs can be estimated using these combined 223 models. Fig.8 shows the forecasts for the four leading PCs of the precipitation data. The forecasts for the 224 first PC obtained using the EOF-ARMA model adequately capture the annual fluctuations, and the fore225 casts for the other PCs also exhibit cyclical fluctuations (Fig. 8a) with smaller amplitudes. The forecasts 226 obtained using the CSEOF-ARMA model continue the interannual and decadal trends observed in the 227 CSEOF analysis (Fig. 8b). The amplitudes of the fluctuations are continuations of the past PCs; this is 228 the goal of the CSEOF-ARMA model.

229 Based on the PC forecasts, precipitation forecasts can be easily extrapolated using the loading vec230 tors (spatial patterns) of the EOF and CSEOF. Quantitative precipitation forecasts are calculated for 56 231 weather stations over five years using the EOF-ARMA and CSEOF-ARMA models, and the results are 232 then checked against the observed precipitation data. Fig. 9 shows scatter plots of the observations and 233 the forecasts resulting from the two models. The forecasts from the EOF-ARMA model are slightly un234 derestimated and are more dispersed than those obtained with the CSEOF-ARMA model (Fig. 9a). In 
236 around the $y=x$ line. This demonstrates the effectiveness of the combined CSEOF-ARMA model.

The mean monthly values of the precipitation forecasts obtained from the two combined models are compared with the observations, as shown in Fig. 10. Because of the effect of the Asian monsoon, rainfall is uneven, with most rainfall occurring in the summer. The EOF-ARMA forecasts are not particularly good, especially for the summer months. However, the CSEOF-ARMA forecasts not only capture the seasonal variations in precipitation but also give confident quantitative predictions of the precipitation amounts.

The mean deviations of the forecasts obtained for the summer monsoon season (June, July, August and September) at each weather station are shown in Fig. 11. The EOF-ARMA model gives higher forecasts in June and September but relatively low forecasts in July and August (Fig. 11a). In contrast, the mean deviation of the forecasts obtained from the CSEOF-ARMA model are much smaller, with small overestimations in June and July and small underestimations in August and September (Fig. 11b).

When the EOF method is used to analyze precipitation time series data, it cannot provide temporal variation responses in the spatial domain when decomposing the time components; thus, some errors result in the distribution analysis. The use of the CSEOF method can make up for this deficiency.

In the spatial distribution of the mean deviation (Fig. 11a and Fig. 11b), the errors spread over the north in June and over the south in July are higher than those in other parts of the study area. We considered that the reason for this result is that precipitation in the south increases obviously and the distribution to almost flip between the two methods.

Several statistical measures are used to evaluate the performances of the forecasting methods: the mean absolute error $(M A E)$, the root mean squared error $(R M S E)$ and the coefficient of determination $258\left(R^{2}\right)$. Table 1 provides a comparison of these measures applied for the two combined models. The results 259 show that both models achieve good performance and that their accuracies are similar. However, the 260 performance of the CSEOF-ARMA model is better than that of the EOF-ARMA model under every 261 measure. The overall results indicate that the CSEOF-ARMA model is an effective approach to precipitation forecasting. 
We investigated the spatiotemporal variability in precipitation data in South Korea using EOF and CSEOF analyses and proposed an effective methodology for precipitation forecasting. Of the total variance in the spatial distribution and temporal evolution of the studied precipitation data, the 13 leading EOF modes accounted for $95.15 \%$ and the 15 leading CSEOF modes accounted for $95.01 \%$. The EOF modes represented cycles with longer time scales than the CSEOF modes; the CSEOF modes represented interannual and decadal variations in the seasonal cycle with stronger natural variabilities than those seen in the EOF modes.

We estimated precipitation forecasts using a regression method. The PC forecasts obtained from the EOF-ARMA model exhibited clear cyclical fluctuations, and those obtained from the CSEOFARMA model represented extensions of the interannual and decadal variations observed in the CSEOF analysis. Based on the PC forecasts, quantitative precipitation forecasts were calculated for 56 stations over five years using the EOF-ARMA and CSEOF-ARMA models; these forecasts were then checked against the observed precipitation data. The results showed that the CSEOF-ARMA model performed

277 better than the EOF-ARMA model. The combined CSEOF-ARMA forecasting model gave the best ap278 proximation performance and captured the variational trends, temporal evolution and recurrent seasonal cycles in the precipitation data. These results indicate that the use of the CSEOF-ARMA model is an accurate and efficient approach to precipitation forecasting in Korea.

Author Contributions: Conceptualization, M. Sun and G. Kim; methodology, Y. Wang; validation, W.

284 Cai; resources, K. Lei. All authors have read and agreed to the published version of the manuscript.

286 Funding This work is supported by the Key Techniques for the Pollutant Source Apportionment and 287 Water Quality Management and their application in the typical contaminated zone of Bohai Sea (No. 288 2018YFC140707600).

\section{Compliance with ethical standards}

291 Conflict of interest The authors declare no conflicts of interest. 
References

Akaike H (1974) A New Look at the Statistical Model Identification. IEEE Transactions on Automatic Control 19(6):716-723. https://doi.org/10.1109/TAC.1974.1100705

Barnston AG, He Y, Glantz MH (1999) Predictive Skill of Statistical and Dynamical Climate Models in SST Forecasts during the 1997-98 El Niño Episode and the 1998 La Niña Onset. Bulletin of the American Meteorological Society 80(2):217-243. https://doi.org/10.1175/15200477(1999)0802.0.CO;2

Becker S, Gemmer M, Jiang T (2006) Spatiotemporal analysis of precipitation trends in the Yangtze River catchment. Stochastic Environmental Research \& Risk Assessment 20(6):435-444. https://doi.org/10.1007/s00477-006-0036-7

Block P, Rajagopalan B (2007) Interannual Variability and Ensemble Forecast of Upper Blue Nile Basin Kiremt Season Precipitation. Journal of Hydrometeorology 8(3):327. https://doi.org/10.1175/JHM580.1

Box GEP, Jenkins GM (1971) Time Series Analysis: Forecasting and Control. Holden-Day, San Francisco. https://doi.org/10.1111/j.1467-9892.2009.00643.x

Cahalan RF, Wharton LE, Wu ML (1996) Empirical orthogonal functions of monthly precipitation and temperature over the United States and homogeneous stochastic models. Journal of Geophysical Research Atmospheres 101(D21):26309-26318. https://doi.org/10.1029/96JD01611

Chang H, Kwon WT (2007) Spatial variations of summer precipitation trends in South Korea, 19732005. Environmental Research Letters 2(4):45012-45019. https://doi.org/10.1088/1748$\underline{9326 / 2 / 4 / 045012}$

Hannachi A, Jolliffe IT, Stephenson DB (2007) Empirical orthogonal functions and related techniques in atmospheric science: A review. International Journal of Climatology 27(9):1119-1152. https://doi.org/10.1002/joc.1499

Higgins RW, Kim HK, Unger D (2004) Long-Lead Seasonal Temperature and Precipitation Prediction Using Tropical Pacific SST Consolidation Forecasts. Journal of Climate 17(17):3398-3414. https://doi.org/10.1175/1520-0442(2004)017<3398:1stapp>2.0.co;2

Huntington TG (2006) Evidence for intensification of the global water cycle: Review and synthesis. Journal of Hydrology 319(1):83-95. https://doi.org/10.1016/j.jhydrol.2005.07.003

Jin YH, Kawamura A, Jinno K, Berndtsson R (2005) Detection of ENSO-influence on the monthly precipitation in South Korea. Hydrological Processes 19(20):4081-4092. https://doi.org/10.1002/hyp.5873

Kim J, Miller NL, Farrara JD, Hong SY (2000) A Seasonal Precipitation and Stream Flow Hindcast and Prediction Study in the Western United States during the 1997/98 Winter Season Using a Dynamic Downscaling System. Journal of Hydrometeorology 1(4):311-329. https://doi.org/10.1175/1525-7541(2000)001<0311:ASPASF>2.0.CO;2

Kim K, Chung C (2001) On the Evolution of the Annual Cycle in the Tropical Pacific. Journal of Climate 14(5):991-994. https://doi.org/10.1175/1520-0442(2001)0142.0.CO;2 Atmospheric Sciences 54(19):2416-2427. https://doi.org/10.1175/1520-0469(1997)0542.0.CO;2 
Kim K, North GR, Huang J (1996) EOFs of One-Dimensional Cyclostationary Time Series: Computations, Examples, and Stochastic Modeling. Journal of the Atmospheric Sciences 53(7):1007-1017. https://doi.org/10.1175/1520-0469(1996)0532.0.CO;2

Kim K, Roh J (2010) Physical Mechanisms of the Wintertime Surface Air Temperature Variability in South Korea and the near-7Day Oscillations. Journal of Climate 23(8):2197-2212. https://doi.org/10.1175/2009JCLI3348.1

Kim K, Wu Q (1999) A Comparison Study of EOF Techniques: Analysis of Nonstationary Data with

$$
\underline{12.1 .185}
$$

Kim KY, Kim YY (2004) Investigation of tropical Pacific upper-ocean variability using cyclostationary EOFs of assimilated data. Ocean Dynamics 54(5):489-505. https://doi.org/10.1007/s10236-004-0094-7

Kim MK, Kang IS, Park CK, Kim KM (2004) Superensemble prediction of regional precipitation over Korea. International Journal of Climatology 24(6):777-790. https://doi.org/10.1002/joc.1029

Kim Y, Kim K-Y, Kim B-M (2013) Physical mechanisms of European winter snow cover variability and its relationship to the NAO. Climate Dynamics 40(7):1657-1669. https://doi.org/10.1007/s00382-012-1365-5

Lim YK, Kim KY (2006) A New Perspective on the Climate Prediction of Asian Summer Monsoon Precipitation. Journal of Climate 19(19):4840-4853. https://doi.org/10.1175/JCLI3905.1

Lorenz EN (1956) Empirical orthogonal functions and statistical weather prediction. MIT, Massachusetts. https://doi.org/10.1134/S1028334X06060377

Nicholls N, Alexander L (2007) Has the climate become more variable or extreme? Progress 19922006. Progress in Physical Geography 31(1):77-87. https://doi.org/10.1177/0309133307073885

North GR, Bell TL, Cahalan RF, Moeng FJ (1982) Sampling Errors in the Estimation of Empirical Orthogonal Functions. Monthly Weather Review 110(7):699. https://doi.org/10.1175/15200493(1982)1102.0.CO;2

Oki T, Kanae S (2006) Global hydrological cycles and world water resources. Science 313(5790):1068-1072. https://doi.org/10.5360/membrane.28.206

Peel S, Wilson LJ (2008) A Diagnostic Verification of the Precipitation Forecasts Produced by the Canadian Ensemble Prediction System. Weather \& Forecasting 23(4):1. https://doi.org/10.1175/2008WAF2006099.1

Schwarz G (1978) Estimating the Dimension of a Model. Annals of Statistics 6(2):461-464. https://doi.org/10.1214/aos/1176344136

Silverman D, Dracup JA (2010) Artificial Neural Networks and Long-Range Precipitation Prediction in California. Japplmeteor 39(1):57-66. https://doi.org/10.1175/1520-0450(2000)0392.0.CO;2

Singh CV (2004) Empirical Orthogonal Function (EOF) analysis of monsoon rainfall and satelliteobserved outgoing long-wave radiation for Indian monsoon: a comparative study. Meteorology \& Atmospheric Physics 85(4):227-234. https://doi.org/10.1007/s00703-003-0013-3

Sun M, Kim G (2016) Quantitative Monthly Precipitation Forecasting Using Cyclostationary Empirical Orthogonal Function and Canonical Correlation Analysis. Journal of Hydrologic Engineering 21(1):123-145. https://doi.org/10.1061/(ASCE)HE.1943-5584.0001244 
Svensson C (1999) Empirical Orthogonal Function Analysis of Daily Rainfall in the Upper Reaches of the Huai River Basin, China. Theoretical \& Applied Climatology 62(3-4):147-161. https://doi.org/10.1007/s007040050080

Trenberth KE (1990) Recent Observed Interdecadal Climate Changes in the Northern Hemisphere. Bulletin of the American Meteorological Society 71(7):377-390. https://doi.org/https://doi.org/10.1175/1520-0477(1990)071<0988:ROICCI>2.0.CO;2

Vautard R, Plaut G, Wang R, Brunet G (1999) Seasonal Prediction of North American Surface Air Temperatures Using Space-Time Principal Components. Journal of Climate 12(2):380-394. https://doi.org/10.1175/1520-0442(1999)0122.0.CO;2

Waliser DE, Jones C, Schemm JKE, Graham NE (1999) A Statistical Extended-Range Tropical Forecast Model Based on the Slow Evolution of the Madden-Julian Oscillation. Journal of Climate 12(7):1918-1939. https://doi.org/10.1175/1520-0442(1999)0122.0.Co;2

Waliser DE, Lau KM, Stern W, Jones C (2003) Potential Predictability of the Madden-Julian Oscillation. Bullamermeteorsoc 84(1):33-50. https://doi.org/10.1175/bams-84-1-33

Wang B, Ding Q, Jhun JG (2006) Trends in Seoul (1778-2004) summer precipitation. Geophysical Research Letters 33(15):292-306. https://doi.org/10.1029/2006GL026418

Wang H, Ting M, Ji M (1999) Prediction of seasonal mean United States precipitation based on El Niño sea surface temperatures. Geophysical Research Letters 26(9):1341-1344. https://doi.org/10.1029/1999GL900230

Webster PJ, Hoyos C (2004) Prediction of Monsoon Rainfall and River Discharge on 15 30-Day Time Scales. Bulletin of the American Meteorological Society 85(11):1745-1765. https://doi.org/10.1175/BAMS-85-11-1745

Zhou BT, Wang H (2006) Relationship between the boreal spring Hadley circulation and the summer precipitation in the Yangtze River valley. Journal of Geophysical Research Atmospheres 111(D16):275-275. https://doi.org/10.1029/2005JD007006 
400 Table 1 Quantitative statistical verification measures of forecasts

\begin{tabular}{cccc}
\hline Index & MAE $(\mathrm{mm})$ & RMSE $(\mathrm{mm})$ & $\mathrm{R}^{2}$ \\
\hline EOF-ARMA & 40.79 & 57.56 & 0.64 \\
CSEOF-ARMA & 25.39 & 38.71 & 0.84 \\
\hline
\end{tabular}




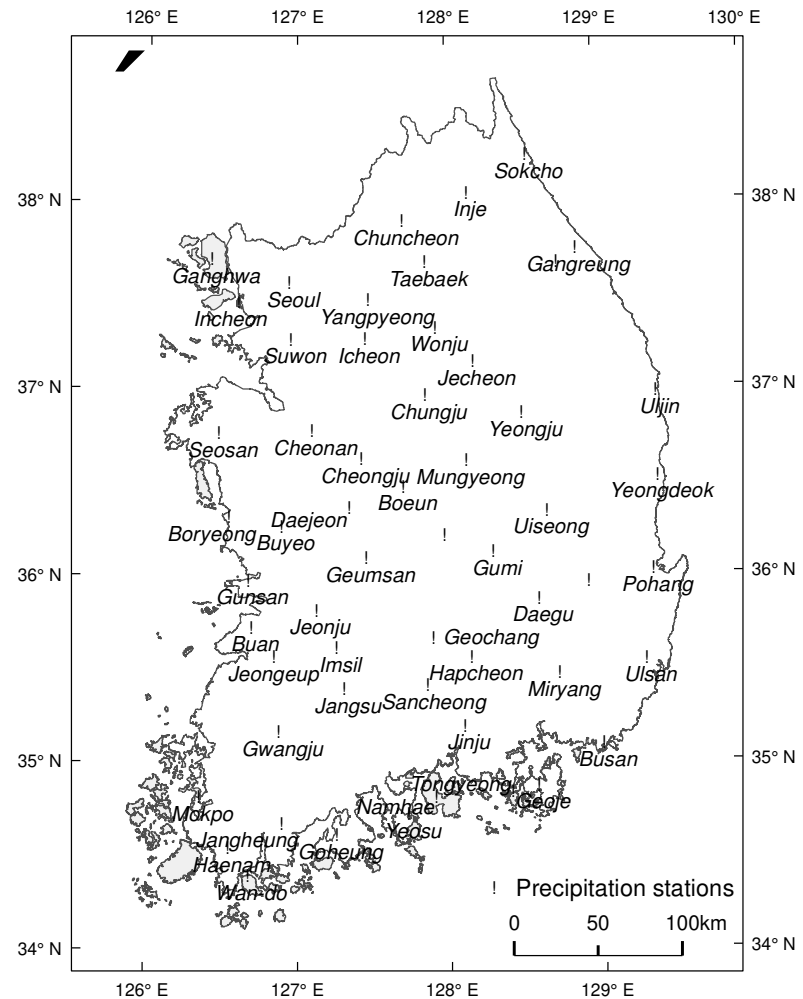

402 Fig. 1 Location of 56 precipitation stations in South Korea.

403 
404

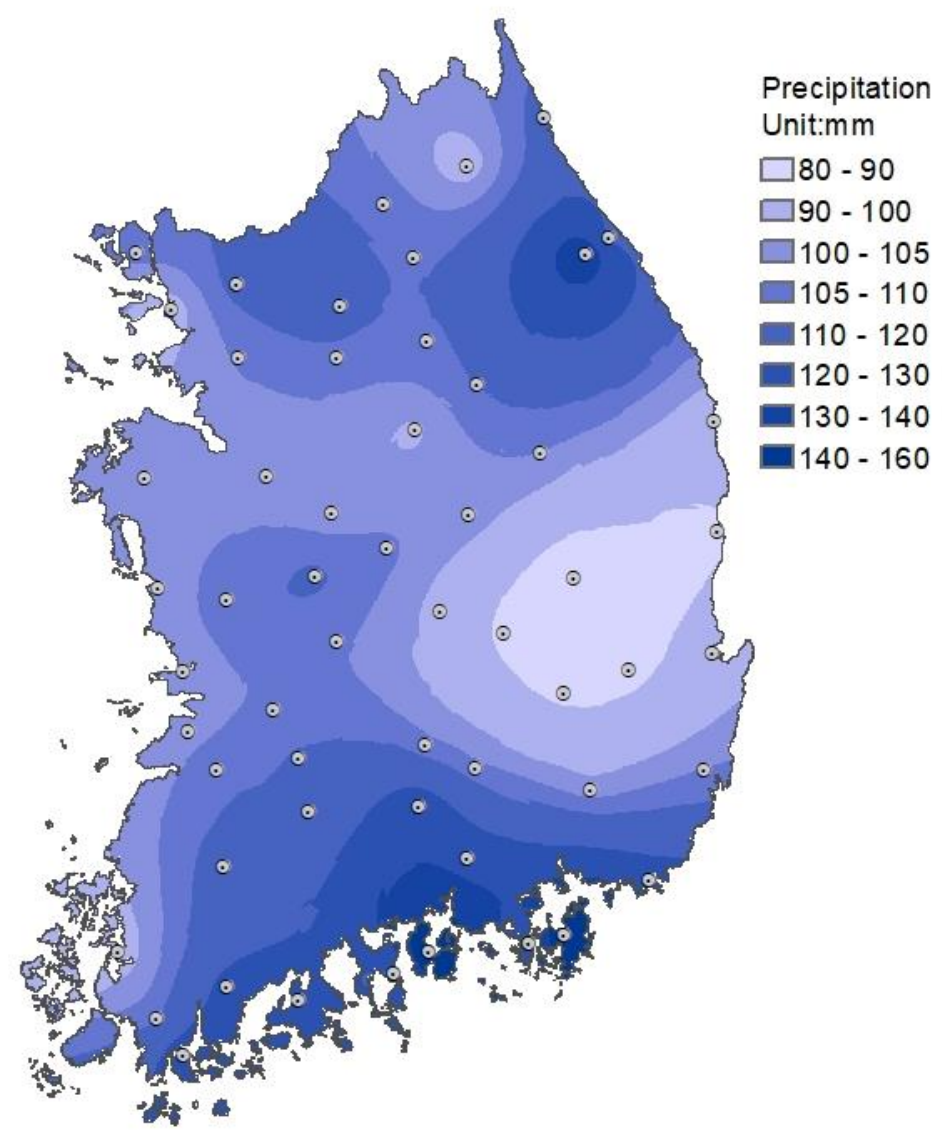

405 Fig. 2 Spatial distribution of mean monthly precipitation data totals from 1973 to 2019 in South Korea 406 


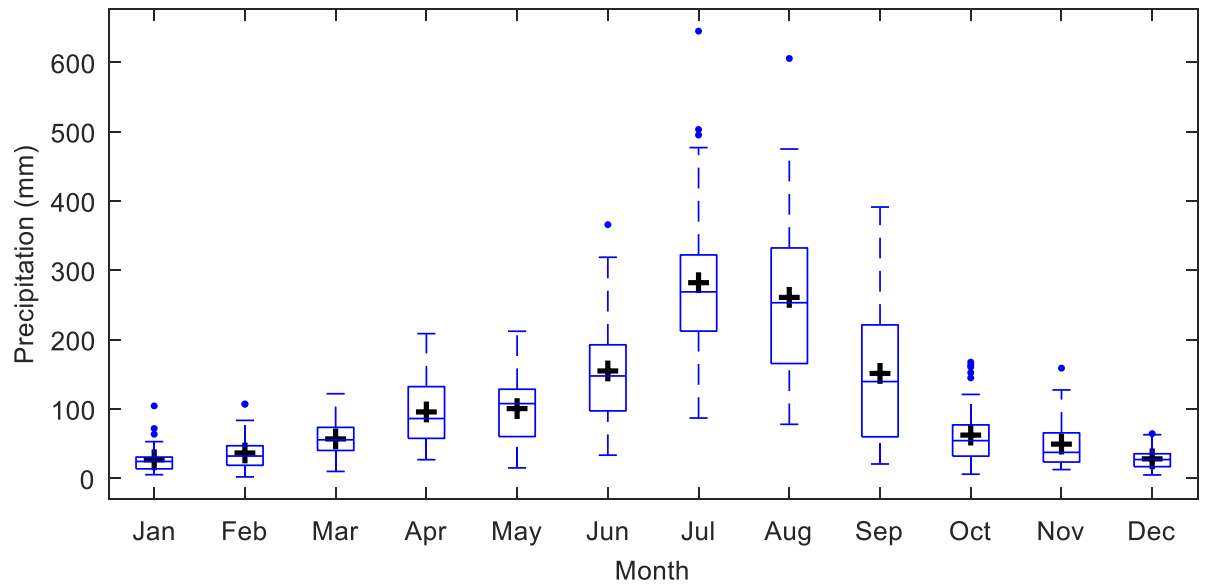

408 Fig. 3 Boxplots of monthly precipitation data totals from 1973 to 2019 in South Korea, The upper and

409 lower boundaries of each box indicate the upper and lower quartiles off the distribution the median values

410 is shown by the cross and line within the box, and the extreme upper data values are shown by dots above

411 and below the box. 

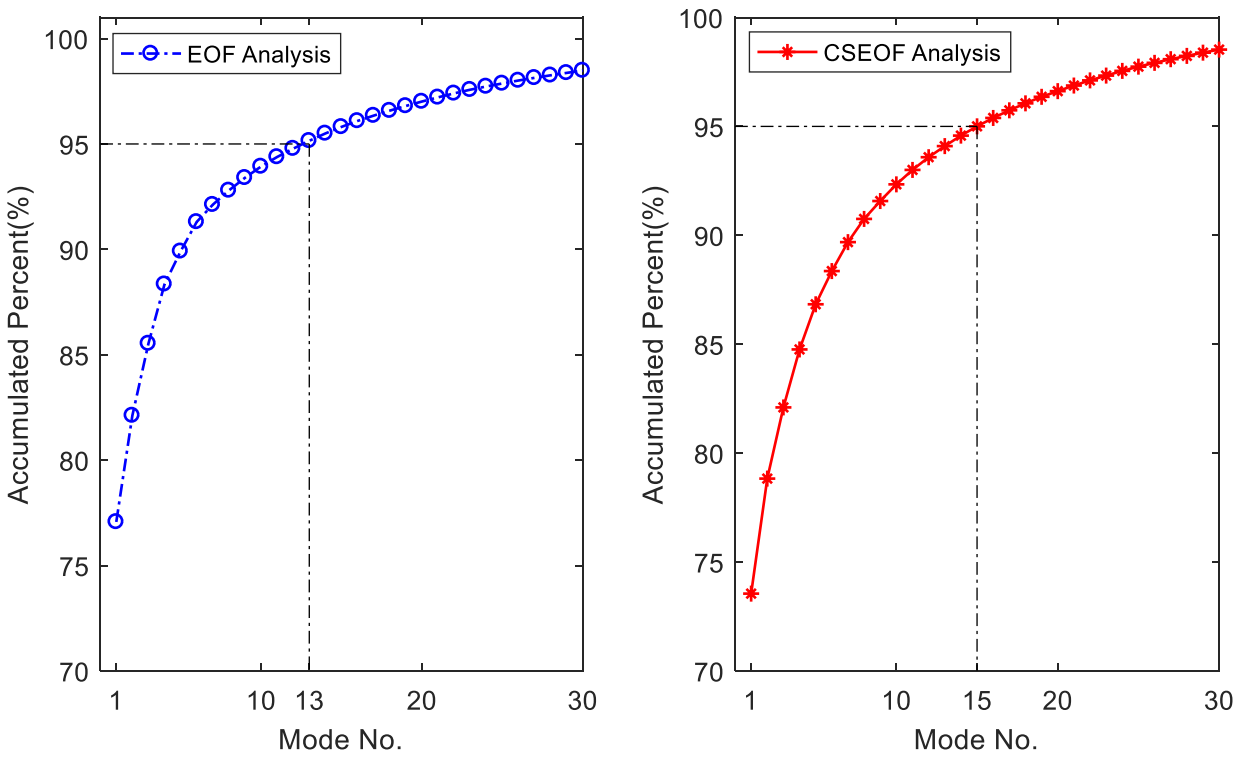

413 Fig. 4 The scree plot of the Accumulated Percent of EOF and CSEOF analysis, 13 leading modes from 414 the EOF, 15 modes form the CSEOF can account above 95\% of total variance. 
(a) 1st EOF Mode $(77.07 \%)$

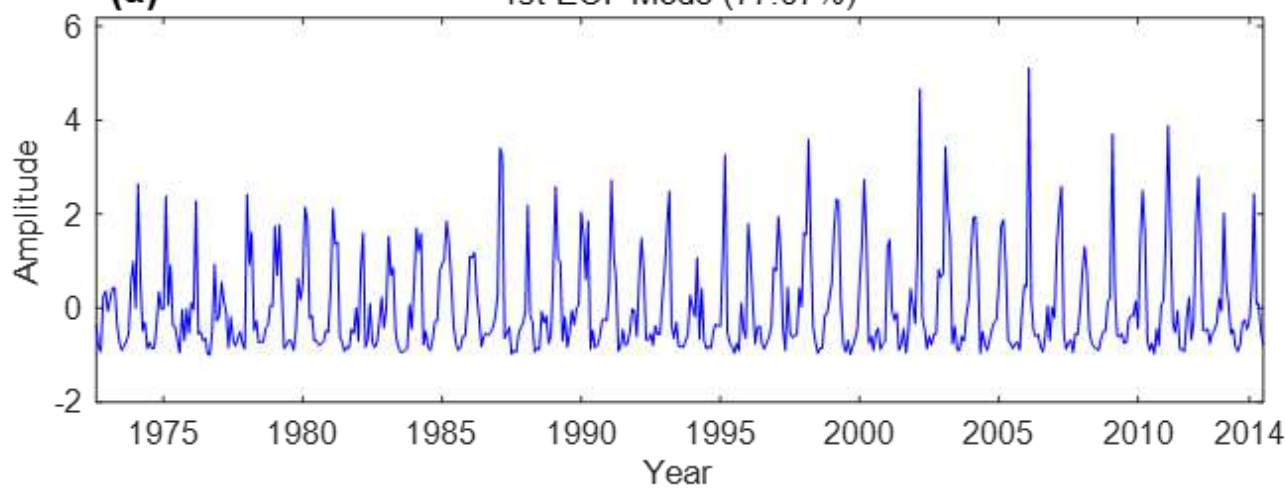

(b) 2nd EOF Mode (8.13\%)

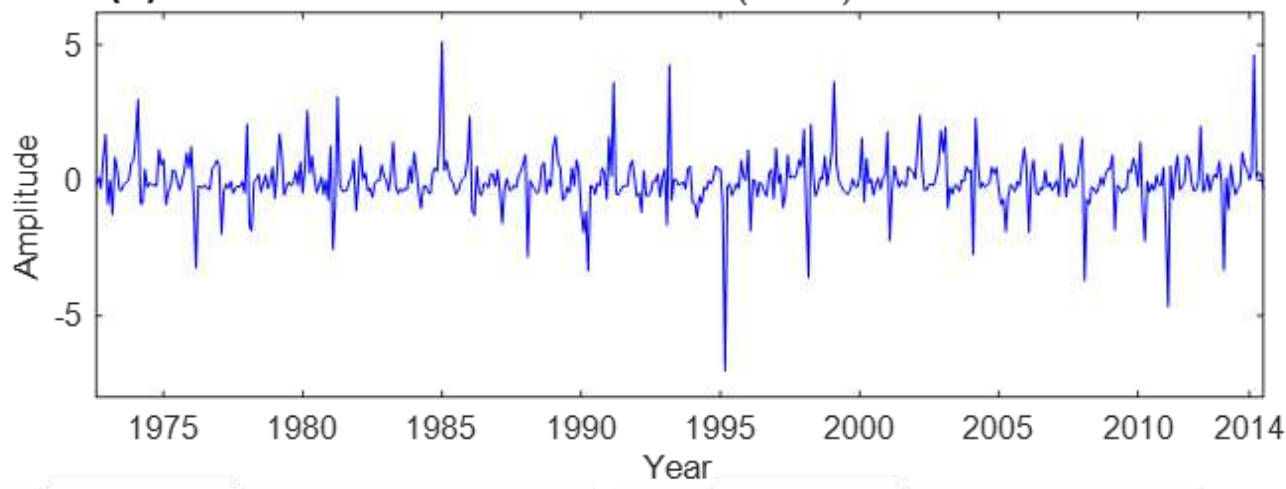

(c)

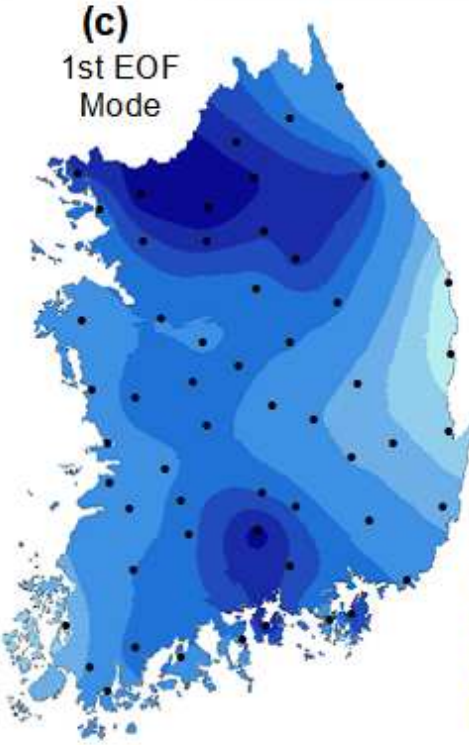

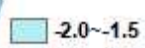

$-1.5 \sim-1.0$

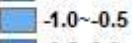

$-0.5 \sim 0.0$
$0.0 \sim 0.5$

$0.5 \sim 1.0$

$1.0 \sim 1.5$

$1.5 \sim 2.0$ (d)

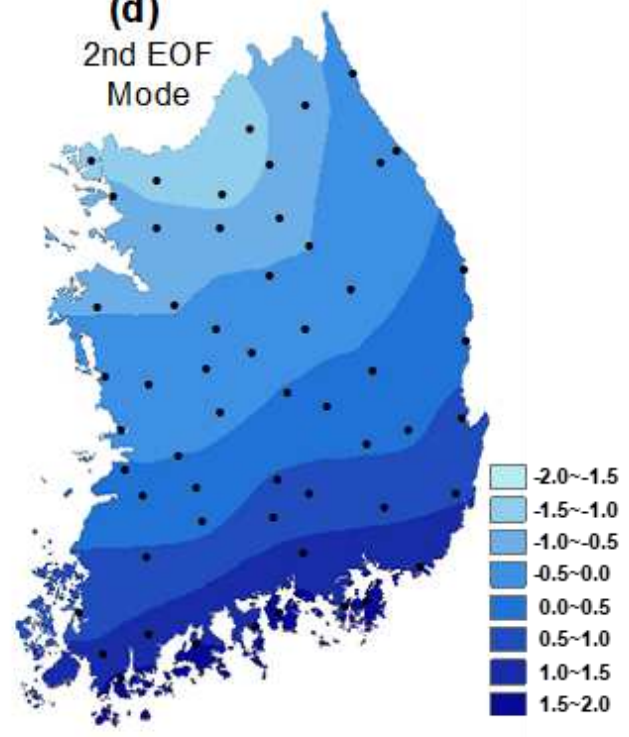

417 Fig. 5 First and second EOF modes of precipitation: (a) principal component time series of 1st EOF

418 mode, (b) principal component time series of 2nd EOF mode, (c) loading vectors of 1st EOF mode, (d)

419 loading vectors of 2nd EOF mode 


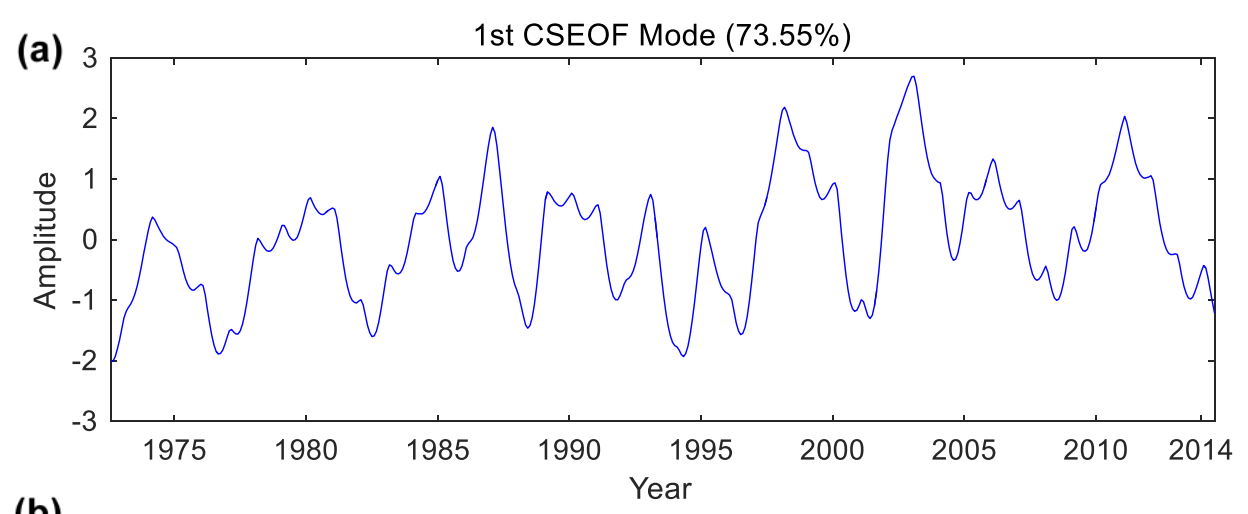

(b)
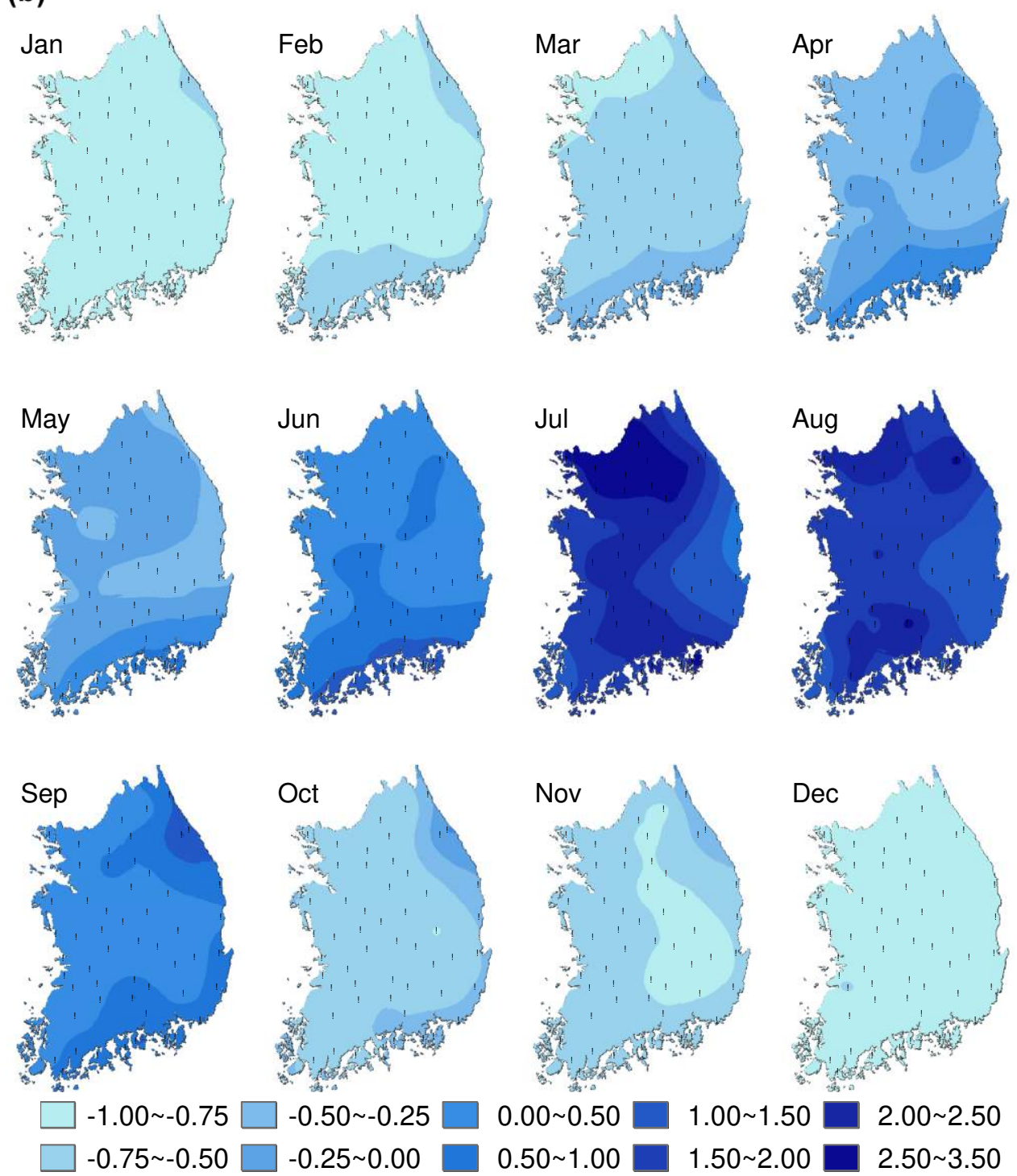

421 Fig. 6 First CSEOF modes of precipitation: (a) principal component time series, (b) Cyclostationary 


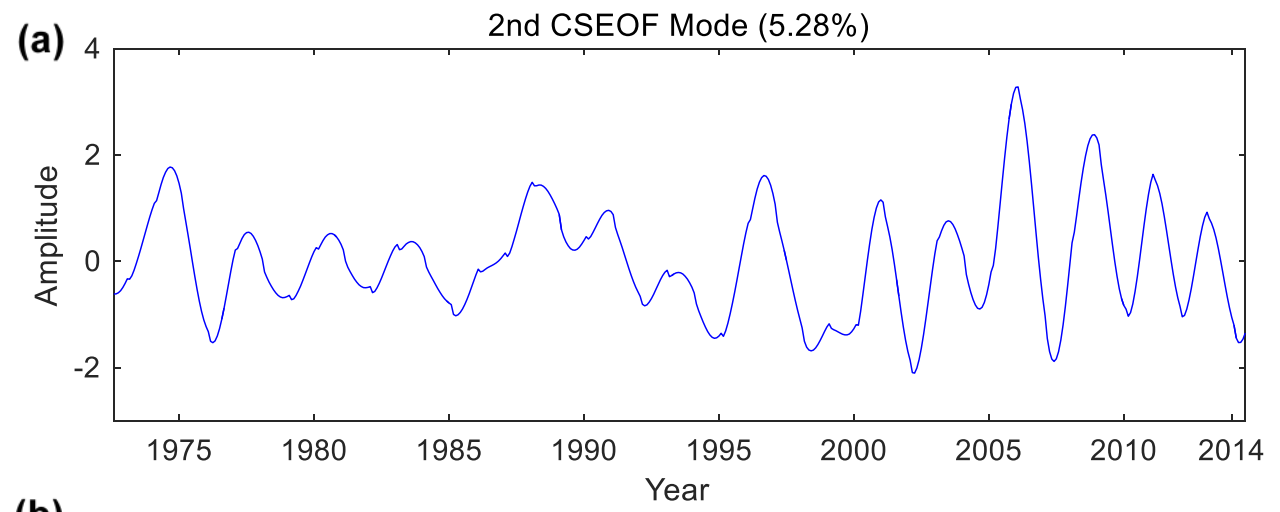

(b)
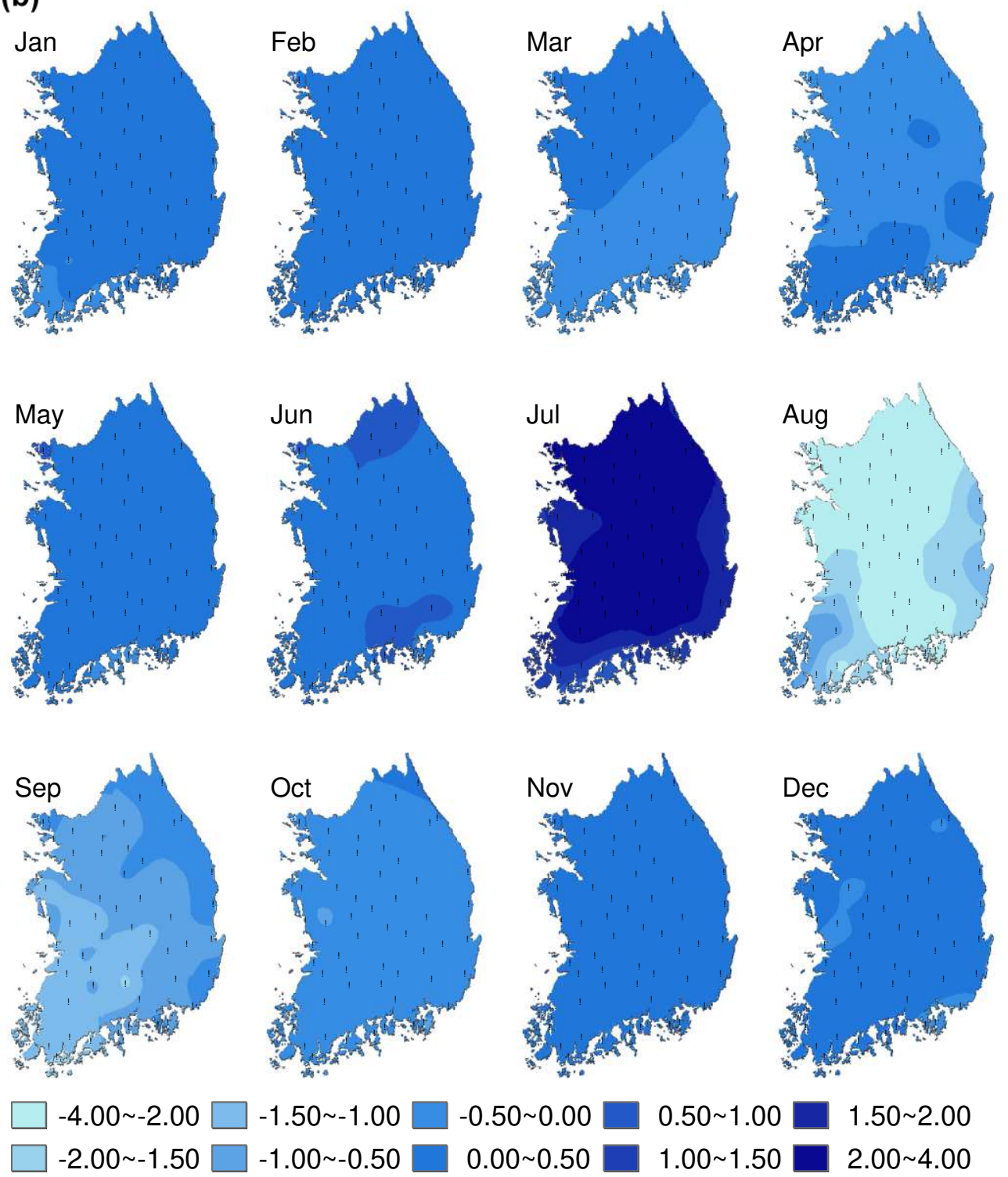

$0.50 \sim 1.00$

$1.50 \sim 2.00$

Fig. 7 Second CSEOF modes of precipitation: (a) principal component time series, (b) Cyclostationary loading vectors (CSLV) 
(a)

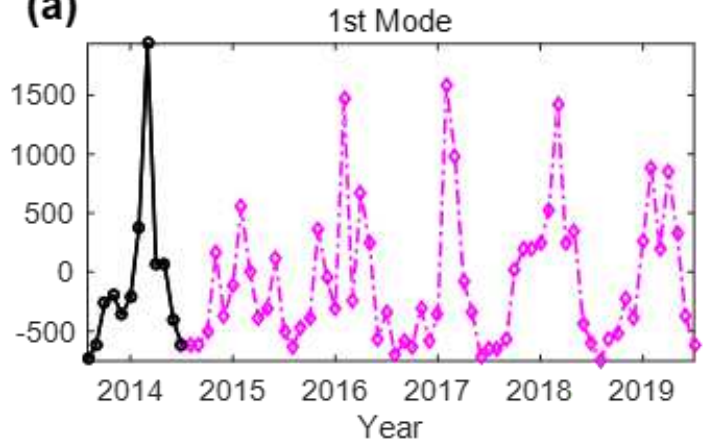

3rd Mode

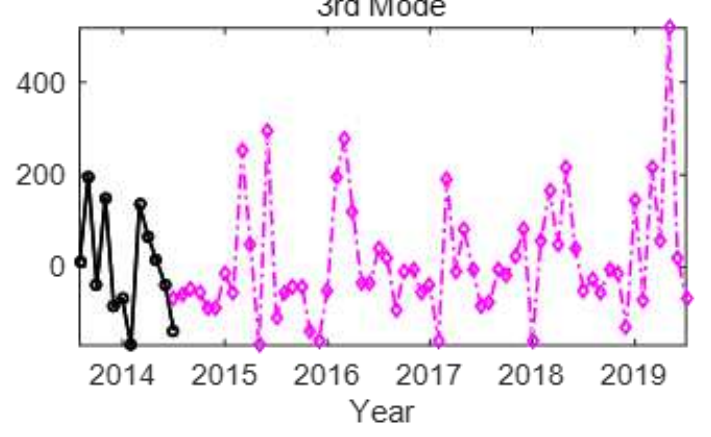

$\longrightarrow$ PC of EOF

(b)
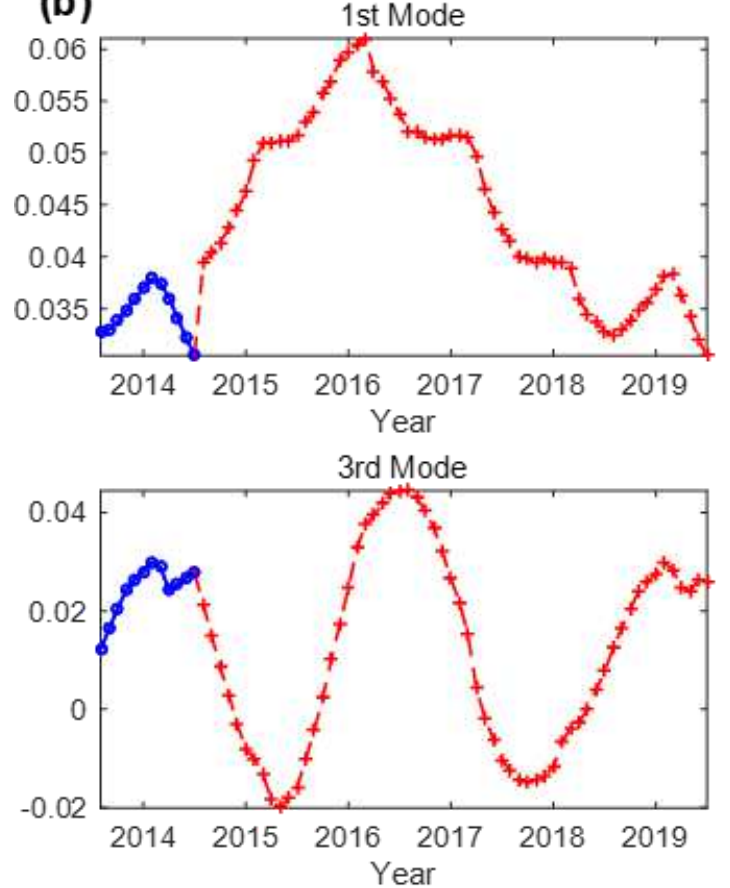

426

427

Fig. 8 Forecasts of principal component time series based on EOF and CSEOF analysis

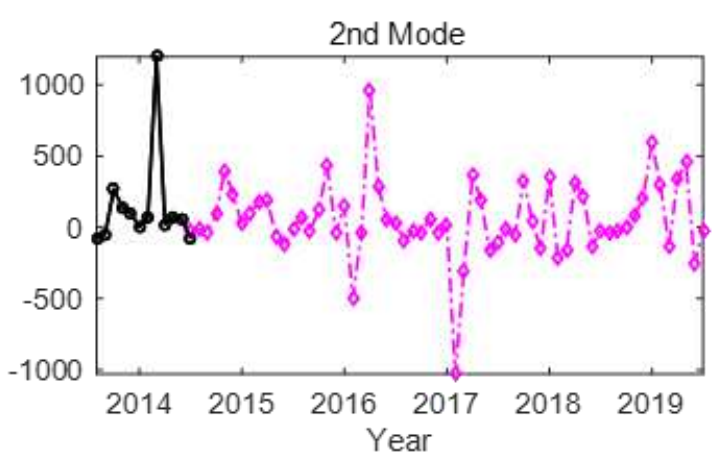

4th Mode

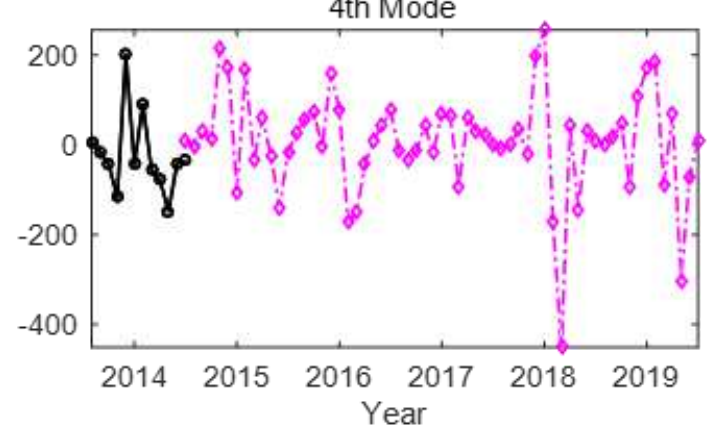

PC Forecasts of EOF
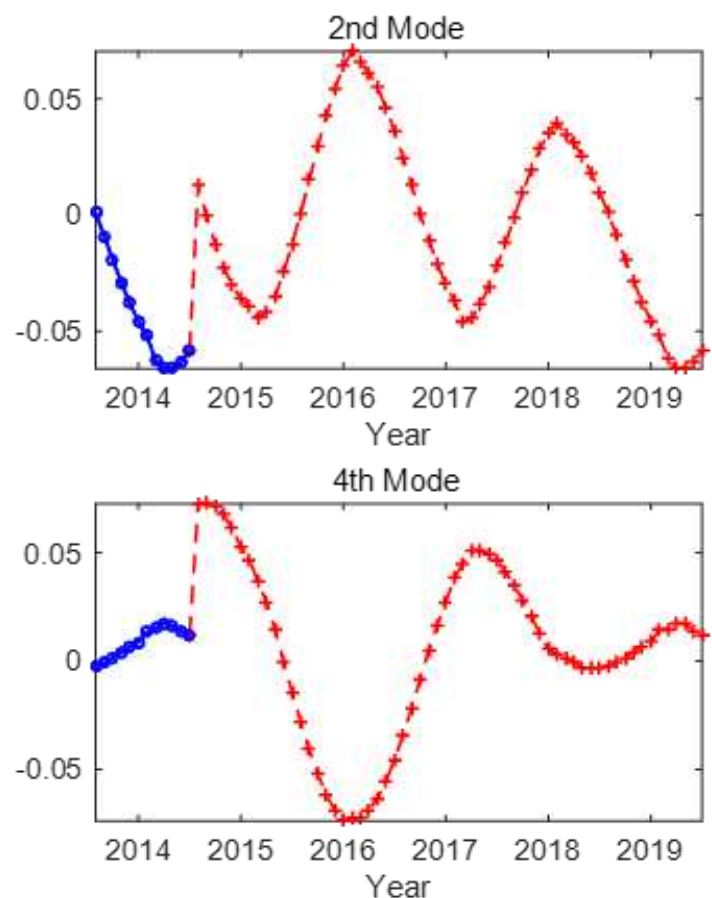

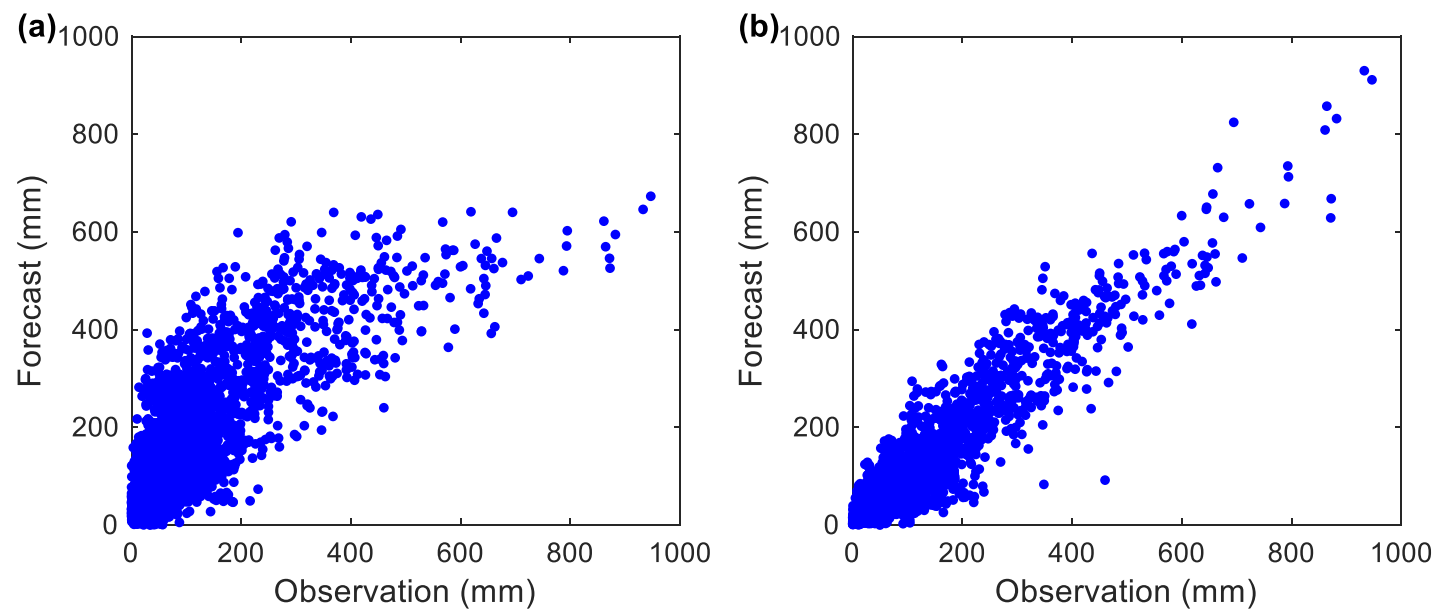

430 Fig. 9 Scatter plots on observation and forecasts of EOF-CCA and CSEOF-ARMA: (a) EOF-CCA fore431 casts, (b) CSEOF-ARMA forecasts 


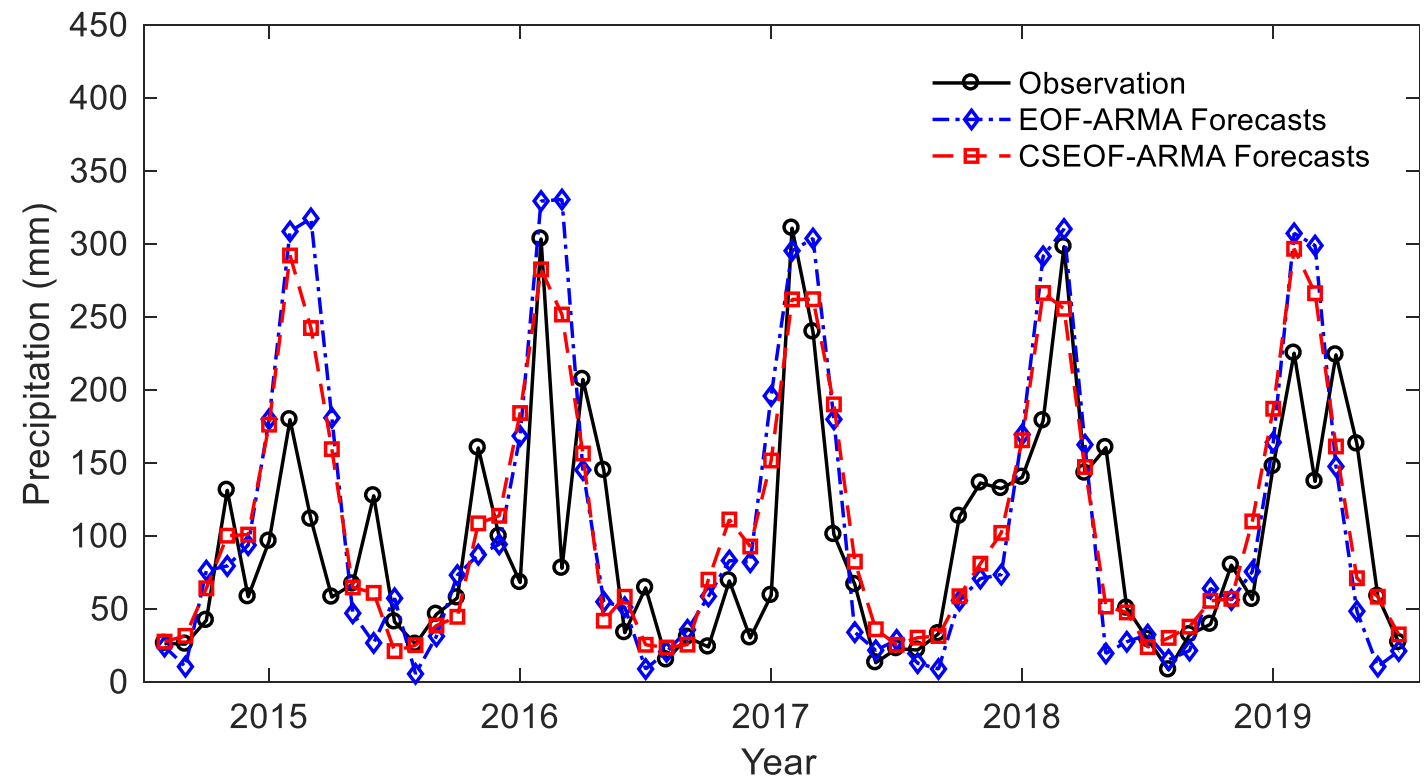

432

433 Fig. 10 Temporal mean of observation with EOF-CCA and CSEOF-ARMA forecasts 
(a)
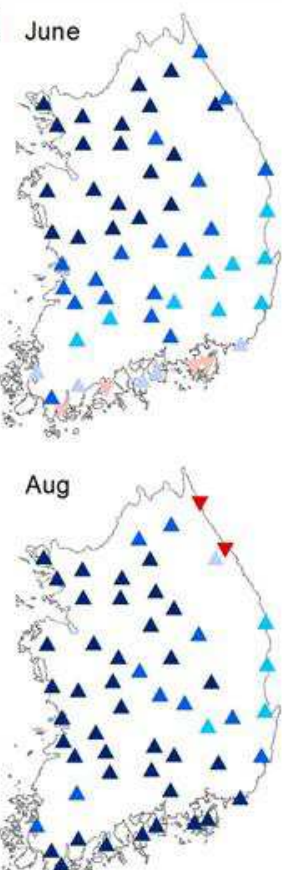
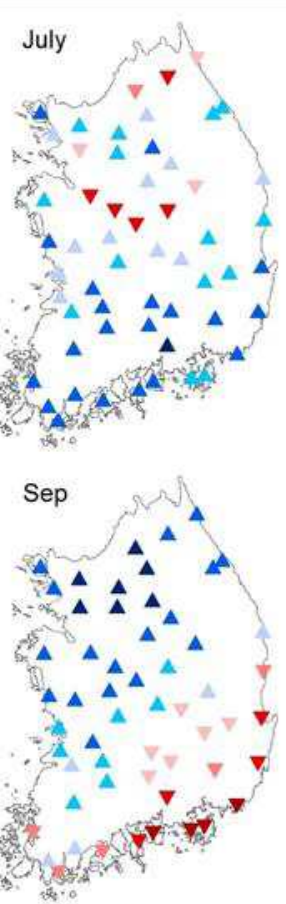

$-150.0 \sim-100.0 \geqslant-50.0 \sim-25.0 \quad 0.0 \sim 25.0 \approx 50.0 \sim 100.0$ $-100.0 \sim-50.0 \quad-25.0 \sim 0.0 \quad$ \& $25.0 \sim 50.0 \wedge 100.0 \sim 150.0$ (b)
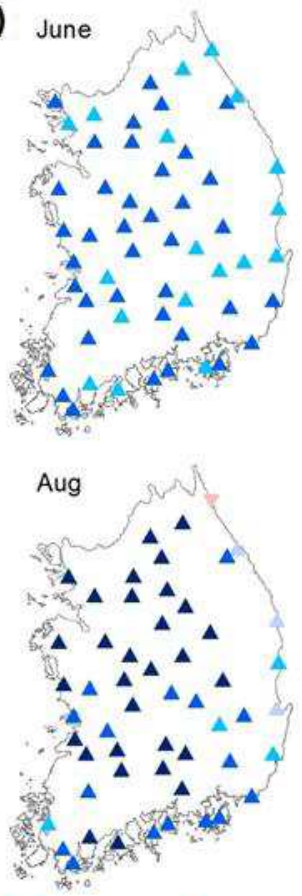

$\nabla-150.0 \sim-100.0>-50.0 \sim-25.0$ A $0.0 \sim 25.0$ A $50.0 \sim 100.0$ $\nabla-100.0 \sim-50.0 \geqslant-25.0 \sim 0.0 \quad 25.0 \sim 50.0 \approx 100.0 \sim 150.0$

Fig. 11 Mean deviation distribution of forecasts of EOF-ARMA and CSEOF-ARMA in June, July, 